OPEN ACCESS

Edited by:

Wong Yau Ho Paul, Tung Wah College, Hong Kong

Reviewed by: Manpreet Kaur Bagga, Partap College of Education, India Izabella Uchmanowicz,

Wroctaw Medical University, Poland

*Correspondence:

Pablo A. Lizana pablo.lizana@pucv.c

Specialty section: This article was submitted to Educational Psychology, a section of the journal

Frontiers in Psychology

Received: 23 July 2019 Accepted: 06 December 2019 Published: 09 January 2020

Citation:

Lizana PA, Vega-Fernandez $G$ and Lera L (2020) Association Between Chronic Health Conditions and Quality of Life in Rural Teachers. Front. Psychol. 10:2898. doi: 10.3389/fpsyg.2019.02898

\section{Association Between Chronic Health Conditions and Quality of Life in Rural Teachers}

\author{
Pablo A. Lizana ${ }^{1 *}$, Gustavo Vega-Fernandez ${ }^{1}$ and Lydia Lera² \\ 'Laboratory of Morphological Sciences, Instituto de Biología, Pontificia Universidad Católica de Valparaíso, Valparaíso, Chile, \\ ${ }^{2}$ Public Nutrition Unit, Institute of Nutrition and Food Technology, University of Chile, Santiago, Chile
}

\begin{abstract}
Aim: The school teacher profession has been reported to be associated with an increased rate of health problems that can affect the quality of life (QoL) of teachers. However, there is little information about rural teachers.
\end{abstract}

Objective: To investigate the associations of obesity, abdominal obesity, and hypertension with the perception of QoL in rural teachers.

Materials and Methods: This cross-sectional study included a representative sample of teachers from eight rural schools in the Valparaíso Region of Chile. Obesity was evaluated by the percentages of fat mass (\% FM) and abdominal obesity, and hypertension was recorded. The Short Form-36 Health Survey was administered to subjects to evaluate QoL. A logistic regression adjusted for age and gender was used to associate QoL with chronic health conditions.

Results: Eighty-five percent of teachers presented abdominal obesity, $56 \%$ presented obesity evaluated by \% FM and 33\% presented hypertension. Thirty percent of teachers in the $\geq 45$-year-old age group presented all three chronic conditions simultaneously. Teachers presenting abdominal obesity in the $\leq 44$-year-old age group had lower scores in the mental health component (MCS) $(p<0.05)$ of the survey than the teachers in the $\geq 45$-year-old age group. In addition, teachers in the $\leq 44$-year-old age group who presented obesity scored lower in the MCS than those in the same age group without obesity $(p=0.004)$. The occurrence simultaneous of two and three chronic health conditions increased the risk of reduced MCS significantly $(p=0.015$, OR 17.0, 95\% Cl: 1.741-165.90 and $p=0.003$, OR 82.6, 95\% Cl: 4.58-1490.70, respectively). In addition, ages under 45 years old were associated with low score of MCS (OR 8.8, 95\% Cl: 1.565-49.698).

Conclusion: A combination of chronic conditions affects the mental health $(\mathrm{MH})$ of rural teachers. Although the association does not imply causation, these findings support the notion that teachers present early $\mathrm{MH}$ problems. This suggests that resources must be made available to detect early mental and chronic health conditions of rural teachers.

Keywords: mental health, physical health, quality of life, school teachers, obesity, hypertension 


\section{INTRODUCTION}

According to the international labor organization (ILO) and the world health organization (WHO), a good occupational health $(\mathrm{OH})$ and quality of life (QoL) standard is achieved with the promotion and maintenance of mental, physical and social wellbeing in all workplaces (OIT, 2003; Bagtasos, 2011). In this sense, one of the professions associated with a large decrease in $\mathrm{OH}$ worldwide is the school teacher (Travers and Cooper, 1993; Johnson et al., 2005; Innstrand et al., 2011); teaching is associated with significant increases in the deterioration of mental health $(\mathrm{MH})$ and physical discomfort during the practice of the profession (Porto et al., 2006; Bauer et al., 2007; Fernandes and Rocha, 2009; Jurado et al., 2019), as well as subsequent psychosocial deterioration (Bringi and Ranbhare, 2015) and QoL disorders due to occupational stress (Yang et al., 2009). It should be noted that one of the problems that contributes to further deterioration of the QoL is the considerable workload outside of the corresponding schedule (OIT, 2003; Bravo, 2005). The United Nations educational, scientific, and cultural organization (UNESCO) has reported similar conditions in Latin American countries such as Mexico, Chile, Peru, Argentina, Ecuador and Uruguay; Chile is ranked first for teachers who work more than $40 \mathrm{~h}$ per week (Cuenca et al., 2005).

Some results in Chile reflect the global situation, where the teaching workload is related to high psychosocial and physical risks and causes a considerable deterioration of the QoL (Cabrera et al., 2003; Cuenca et al., 2005). It is also important to point out that these professionals have a higher disease recurrence rate than the country average (Chávez, 2009), an aspect that has also been reported in other countries (Unterbrink et al., 2008; Bogaert et al., 2014).

The population of teachers in Chile belongs almost entirely to the age ranges of 25-44 and 45-64 years old, which are two of the four age categories studied by the National Health Survey of Chile (Ministerio de Salud de Chile, 2010a). The majority of the working population, particularly those that present diverse health risks due to the prevalence of some chronic noncommunicable diseases (CNCDs) related to nutritional status and body composition, is concentrated in these two age ranges. For example, obesity according to body mass index (BMI) ( $\geq 25)$ has a considerable prevalence of $72.26 \%$ in both age categories, and a prevalence of $43.8 \%$ for high blood pressure has been reported for those 45-64 years old (Ministerio de Salud de Chile, 2010a). In this sense, teachers $\geq 45$ years old have a lower working capacity than teachers $\leq 45$ years old (Freude et al., 2005). Therefore, identifying factors that influence health by age category is relevant for the development of public policies.

In Chile, the rates of overweight, obesity, and abdominal obesity are higher in women from rural areas than in women from urban areas (Ministerio de Salud de Chile, 2010a), which is an important factor since females are mainly employed in the teaching profession (Cabrera et al., 2003; Cuenca et al., 2005). In addition, chronic conditions significantly affect the perception of QoL (Vinaccia and Orozco, 2005; Trevisol et al., 2011; Pimenta et al., 2015), and therefore a decreased QoL may also be present in the population of teaching professionals. However, among the studies on Chile's workforce, there have been no reports of research on CNCDs in teachers and the impact of these conditions on the perception of QoL in rural teachers.

\section{MATERIALS AND METHODS}

\section{Participants}

The target population was all teachers working in eight rural primary schools $(N=97)$ in rural establishments in the communities of Calera $\left(32^{\circ} 47^{\prime} 0^{\prime \prime} \mathrm{S}, 71^{\circ} 13^{\prime} 0^{\prime \prime} \mathrm{W}\right)$ and Hijuelas $\left(32^{\circ} 48^{\prime} 0^{\prime \prime} \mathrm{S}, 71^{\circ} 10^{\prime} 0^{\prime \prime} \mathrm{W}\right)$, Valparaíso, Chile (MINEDUC, 2016). To calculate the sample size, the variable with the greatest variance for this group was selected according to the literature published at the time of planning of this study. The sample was determined with the variable BMI (Ministerio de Salud de Chile, 2010a) for adults of the Valparaíso region. The sample was calculated with $95 \%$ confidence and a 5\% error. The minimum sample size was calculated as 69 teachers.

Sampling was conducted between April and July 2016. Eighty teachers agreed to participate in the study. The final sample consisted of 70 teachers; 10 teachers were excluded for the following reasons: incomplete data (5), pregnancy (1), and sick leave at the time of the evaluation (4). The teachers presented ages ranging from 24 to 64 years, with an average age of $40.78 \pm 12.57$ years; $68.6 \%$ of the teachers were women. All teachers were evaluated in the same educational establishments during morning sessions.

\section{Instruments}

\section{Anthropometry, Body Composition, and Cardiovascular Risk}

The weight and height of the subjects were evaluated to determine the BMI (height in meters/kilograms squared), which was categorized as underweight $\left(\right.$ BMI $\left.<18.5 \mathrm{~kg} / \mathrm{m}^{2}\right)$, normal weight $\left(18.5 \mathrm{~kg} / \mathrm{m}^{2} \leq \mathrm{BMI}<25 \mathrm{~kg} / \mathrm{m}^{2}\right)$, overweight $\left(25 \mathrm{~kg} / \mathrm{m}^{2} \leq \mathrm{BMI}<30 \mathrm{~kg} / \mathrm{m}^{2}\right)$, or obese $\left(\mathrm{BMI} \geq 30 \mathrm{~kg} / \mathrm{m}^{2}\right)$. To evaluate obesity based on the percentage of fat mass (\% FM), a bioelectrical impedance device was used (TANITA BC 420 SMA, Tanita, Tokyo, Japan); the subjects were asked not to carry metallic objects, drink alcohol $48 \mathrm{~h}$ before the evaluation, perform intense exercise $12 \mathrm{~h}$ before the evaluation, eat or drink, especially caffeine or diuretics, $4 \mathrm{~h}$ before the evaluation, and were asked to urinate before the evaluation. To classify obesity by \% FM, the recommendation by the "American Society of Endocrinologists" was adopted; the cutoff points were $>35 \%$ in women and $>25 \%$ in men (Flegal et al., 2012).

The waist circumference (abdominal fat marker) was measured abdominally at the level of the iliac crest and after a normal exhalation while the subject was in a standing position. The tape measure (Lufkin ${ }^{\mathrm{TM}}$ ) was adjusted without compressing the structures. The protocol was outlined in the Clinical Guidelines for Obesity of the United States National Institute of Health (NIH) and was replicated in the National Health Survey from Chile 2003 and 2009-2010 (Ministerio de Salud de Chile, 2010a). The suggested cutoff points were $\geq 102 \mathrm{~cm}$ for men and $\geq 88 \mathrm{~cm}$ for women. 
Blood pressure was measured using automated sphygmomanometers (OMRON HEM-705CPINT; Omron Co., Kyoto, Japan). The evaluation protocol involved placing the subject in a sitting and relaxed position for at least 5 min with the left upper limb supported on a table at the level of the heart; the cuff was then placed and adjusted to the perimeter of the subject's arm. A classification of high blood pressure was a systolic pressure $\geq 140 \mathrm{mmHg}$ and a diastolic pressure $\geq 90 \mathrm{mmHg}$, according to the clinical guidelines of arterial hypertension outlined by the Ministry of Health of Chile (Ministerio de Salud de Chile, 2010b). For subjects who presented high blood pressure, the procedure was repeated after a ten-minute rest, and the average of three readings performed at an interval of 2 min was considered, similar to the procedure performed in the National Health Survey 2009-2010 (Ministerio de Salud de Chile, 2010a).

\section{Quality of Life Questionnaire}

The QoL of the teachers was evaluated using the Short-Form 36 Health Survey (SF-36) questionnaire, which is an instrument developed in the United States to evaluate QoL-related health in adults (Ware and Sherbourne, 1992); the SF-36 has been adapted syntactically and semantically for the Chilean population (Olivares, 2006). The questionnaire includes 36 items measured on a Likert scale. The 36 items are grouped into 8 health topics: physical function (FF), physical role (PR), body pain (BP), general health perception $(\mathrm{GH})$, vitality $(\mathrm{VT})$, social function (SF), emotional role (ER), and $\mathrm{MH}$. The 8 topics can be categorized into two components, the physical component summary (PCS) and the mental component summary (MCS). For each scale, T scores, with an average of 50 and a standard deviation of 10 , were calculated (McDowell and McDowell, 2006).

\section{Procedure}

Procedures for anthropometric measurements, body composition analysis using bioimpedance, and the SF-36 questionnaire were orally explained to the teachers. In addition, the subjects signed an informed consent form to indicate that they understood the scope of the investigation. Participation in the study was voluntary and the anonymity of teachers was guaranteed. This study was approved by the Ethics Committee of the Pontificia Universidad Católica de Valparaíso in accordance with the Declaration of Helsinki (The World Medical Association, 2009).

\section{Data Analysis}

Statistical analyses were performed using STATA 15 software (2017, Stata Corp. LLC, College Station, TX, United States). In this cross-sectional study, descriptive analyses are presented as the mean, standard deviation (mean \pm SD) and percent according to age category $(\leq 44$ years old and $\geq 45$ years old), cutoff scores for age were obtained from the National Health Survey of Chile of Chile (Ministerio de Salud de Chile, 2010a). Comparisons of anthropometric measurements, body compositions and each item of the QoL questionnaire between the groups were carried out using specifics test ( $t$-test or its non-parametric equivalent according to Shapiro Wilk's normality tests). The chi-square $(\chi 2)$ test was used to evaluate the associations between obesity by BMI, obesity by \% FM, abdominal obesity and blood pressure by age category, as well as to evaluate their associations with chronic conditions (obesity by \% FM, abdominal obesity and arterial hypertension). The 25th percentiles (25p) of each summary factor (MCS and PCS) were used as a cut-point to dichotomize the data. The teachers were classified in low (below 25p) or fair/good (above $25 \mathrm{p})$ categories. Logistic regression analysis was performed to estimate the association between low scores of MCS and PCS factors with chronic conditions adjusted by age and gender. To verify the accuracy of fit of the model, the Hosmer-Lemeshow test was applied.

\section{RESULTS}

\section{Characteristics of the Subjects}

The total number of subjects participating in this study, their sociodemographic characteristics, and their health characteristics, including body composition, hypertension status, and chronic health conditions, are shown in Table 1. The total sample of the evaluated teachers was 70 individuals $(68.57 \%$, women), with an average age of $40.79 \pm 12.58$ years; the age categories of $\leq 44$ years old and $\geq 45$ years old represented $61.42 \%$ and $38.57 \%$ of the sample population, respectively, resulting in an average age of $31.62 \pm 4.94$ years for the first group and $55.37 \pm 4.53$ years for the second group.

\section{Body Composition and Chronic Conditions}

The study sample did not present significant differences between the two age categories in terms of weight $(p=0.209)$ and height $(p=0.132)$. Regarding BMI, both age groups showed significant differences $(p=0.022)$, with the second group having the highest BMI $\left(28.55 \pm 3.64\right.$ vs. $\left.26.32 \pm 4.00 \mathrm{~kg} / \mathrm{m}^{2}\right)$. In turn, the association between age and BMI was also significant ( $p=0.028$ ); both age groups had a high prevalence of overweight, at $41.86 \%$ ( $\leq 44$ years old) and $51.85 \%$ ( $\geq 45$ years old), with an evident tendency for BMI to increase with age. Additionally, it was observed that the highest prevalence of obesity was found in the older group, at $18.60 \%$ vs. $37.03 \%$ in the younger group (Table 1).

Waist circumference was significantly greater in the older age group than in the younger age group $(p=0.010)$, and a majority $(85.71 \%)$ of the total sample presented abdominal obesity. In addition, waist circumference associated with abdominal obesity was more prevalent in subjects $\geq 45$ years old $(79.6 \%$ in the younger age range vs. $96.29 \%$ in the older age range, $p=0.045$ ).

Fat mass $(\mathrm{kg})$ was not significantly different between the age categories $(p=0.055)$, nor was the variable of fat-free mass (FFM, kg) $(p=0.542)$. However, the results of\% FM showed a significant difference $(p=0.022)$ between the age two ranges; \% FM was higher in the older age group than in the younger age group (Table 1). In addition, the results suggested a significant association $(p<0.001)$ between the age of the subjects and the 
TABLE 1 | Sociodemographic and health characteristics of rural teachers in Valparaiso, Chile stratified by age group.

\begin{tabular}{|c|c|c|c|c|}
\hline & Total sample & $\leq 44$ & $\geq 45$ & \\
\hline & Mean \pm SD & Mean \pm SD & Mean \pm SD & $P$ \\
\hline Age (years) & $40.79 \pm 12.58$ & $31.62 \pm 4.94$ & $55.37 \pm 4.53$ & $<0.01^{a}$ \\
\hline Weight (Kg) & $71.30 \pm 12.14$ & $69.85 \pm 13.15$ & $73.61 \pm 10.14$ & $0.209^{a}$ \\
\hline Height (m) & $1.61 \pm 0.09$ & $1.62 \pm 0.08$ & $1.59 \pm 0.08$ & $0.132^{a}$ \\
\hline $\mathrm{BMI}\left(\mathrm{kg} / \mathrm{m}^{2}\right)$ & $27.18 \pm 3.99$ & $26.32 \pm 4.00$ & $28.55 \pm 3.64$ & $0.022^{a}$ \\
\hline Normal weight & $20(28.57)$ & 17 (39.53) & $3(11.11)$ & $0.028^{c *}$ \\
\hline Overweight ${ }^{\mathrm{e}}$ & $32(45.71)$ & $18(41.86)$ & $14(51.85)$ & \\
\hline Obese $e^{e}$ & $18(25.71)$ & $8(18.60)$ & $10(37.03)$ & \\
\hline $\begin{array}{l}\text { Waist } \\
\text { circumference } \\
(\mathrm{cm})\end{array}$ & $94.30 \pm 10.30$ & $91.83 \pm 10.46$ & $98.24 \pm 8.87$ & $0.010^{a}$ \\
\hline Normal waist ${ }^{e}$ & $10(14.28)$ & $9(20.43)$ & $1(3.70)$ & $0.045^{c *}$ \\
\hline Central obesity ${ }^{\mathrm{e}}$ & $60(85.71)$ & $34(79.06)$ & $26(96.29)$ & \\
\hline Fat mass $(\mathrm{Kg})^{\mathrm{d}}$ & $23.76 \pm 8.37$ & $22.24 \pm 9.05$ & $26.17 \pm 6.62$ & $0.055^{a}$ \\
\hline Fat mass $(\%)^{d}$ & $32.99 \pm 8.75$ & $31.10 \pm 9.05$ & $35.99 \pm 7.44$ & $0.022^{a}$ \\
\hline Normale & $31(44.28)$ & $26(60.46)$ & $5(18.51)$ & $<0.001^{c}$ \\
\hline Obese $e^{e}$ & $39(55.71)$ & $17(39.53)$ & $22(81.48)$ & \\
\hline FFM $(K g)^{d}$ & $48.14 \pm 9.20$ & $47.60 \pm 8.47$ & $48.99 \pm 10.37$ & $0.542^{b}$ \\
\hline FFM $(\%)^{d}$ & $66.86 \pm 9.04$ & $68.89 \pm 9.05$ & $63.63 \pm 8.18$ & $0.017^{a}$ \\
\hline Systolic & $130.29 \pm 18.75$ & $123.90 \pm 15.11$ & $140.44 \pm 19,72$ & $<0.001^{a}$ \\
\hline Diastolic & $75.44 \pm 11.34$ & $7.32 \pm 10.23$ & $77.22 \pm 12.91$ & $0.302^{a}$ \\
\hline Normal pressure ${ }^{\mathrm{e}}$ & $47(67.14)$ & $34(79.07)$ & $13(48.15)$ & $0.008^{c}$ \\
\hline Hypertension ${ }^{\mathrm{e}}$ & $23(32.86)$ & $9(20.93)$ & $14(51.85)$ & \\
\hline \multicolumn{5}{|l|}{$\begin{array}{l}\text { Chronic } \\
\text { condition } \\
\text { combination }^{f}\end{array}$} \\
\hline Normal $^{e}$ & $15(21.42)$ & $14(32.55)$ & $1(3.70)$ & \\
\hline One condition ${ }^{e}$ & $17(24.28)$ & $12(27.90)$ & $5(18.51)$ & $<0.001^{c}$ \\
\hline Two conditions $^{e}$ & $28(40.00)$ & $15(34.88)$ & $13(48.14)$ & \\
\hline Three conditions ${ }^{e}$ & $10(14.28)$ & $2(4.56)$ & $8(29.62)$ & \\
\hline
\end{tabular}

BMI, body mass index; SD, standard deviation; FFM, free fat mass ( $\mathrm{kg} \& \%$ ). ( $\leq 44-\geq 45$ ), age categories (years). $P<0.05 .{ }^{a}$ t-test. ${ }^{b}$ Mann-Whitney-Test. ${ }^{C}$ Chisquared. ${ }^{*}$ Fisher's exact test. ${ }^{d}$ Body components evaluated by bioimpedance (TANITA BC 420SMA). ${ }^{e}$ Data are expressed as frequency (percentage). ${ }^{f}$ Chronic conditions: hypertension, central obesity, and obesity.

presence of obesity, with the prevalence of obesity increasing from $39.53 \%$ in the younger group to $81.48 \%$ in the older group. The \% FFM was significantly different between the age groups and was higher in subjects $\leq 44$ years old than in subjects $\geq 45$ years old $(68.89 \pm 9.05$ vs. $63.63 \pm 8.18, p=0.017)$.

Systolic blood pressure was significantly higher $(p<0.01)$ in the older age group. Diastolic pressure was not significantly different between the two age groups $(p=0.302)$; however, these age ranges had a significant association $(p=0.008)$ with hypertension, which tends to occur with age. The older age group had a hypertension prevalence rate of more than $50 \%$.

In the combined analysis of obesity by \% FM, abdominal obesity and hypertension in relation to the presence of one, two, or all three chronic conditions in the respective age groups, significant associations were observed with the presence of all three chronic conditions in the older age category $(4.56 \%$ vs. $29.62 \%, p=0.010$ ) (Table 1).

\section{Perception of Quality of Life}

Table 2 shows a comparison of the average scores of each of the eight scales and the two summary measures of the SF-36 survey; results are stratified by age and the presence and absence of each chronic condition. For the subjects in the younger age group, there were significant associations between the presence and absence of abdominal obesity and the QoL scores for both the MCS measures $(p=0.001)$ and four of the eight survey scales (PF, RE, BP, and GH; $p=0.046, p=0.018, p=0.001$, and $p=0.042$, respectively), while for the older age group, there were no significant differences. In the overall sample of teachers, significant differences were also shown; Abdominal obesity was associated with a deterioration in the QoL in four of the eight scales of the survey (PF, RE, BP, and GH; $p=0.014$, $p=0.027, p<0.001$, and $p=0.034$, respectively) as well as the MCS $(p=0.012)$. Regarding hypertension, there were no significant differences between age groups for conditions associated with QoL scales. For the chronic condition of obesity in the younger age group, significant differences were found between the presence and absence of obesity for one of the eight QoL scales (RE; $p=0.026$ ), as well as for the MCS measure $(p=0.004)$. No significant differences were observed for the older age group. Nonetheless, in the total sample, there were significant differences in obesity for three scales of the QoL survey (PF, $\mathrm{RE}$, and $\mathrm{MH} ; p=0.035, p=0.044$, and $p=0.036$, respectively); however, none were observed for the summary measures.

Table 3 shows that $\%$ FM and abdominal obesity have significant associations with a poor perception of QoL in the MCS in the younger age group ( $p<0.005)$. In addition, abdominal obesity also presented a significant association with the PCS in the $\leq 44$-year-old age group ( $p=0.037)$.

The results for the association of 25th percentiles of MCS and PCS with chronic health conditions variables adjusted by age and gender are given in Table 4. The association between chronic health conditions and PCS was not significant. However, the occurrence simultaneous of two and three chronic health conditions increased the risk of reduced MCS significantly ( $p=0.015$, OR 17.0, 95\% CI: $1.741-165.90$ and $p=0.003$, OR 82.6, 95\% CI: 4.58-1490.70, respectively). In addition, ages under 45 years old were associated with low MCS $(p=0.014$, OR 8.8, 95\% CI: 1.565-49.698), but the association with gender was insignificant.

\section{DISCUSSION}

This study found that teachers from rural locations had a high prevalence of CNCDs and that each of the studied CNCDs increased in subjects $\geq 45$ years old. The prevalence of overweight at ages 25-44 and 45-64 years, as reported in the National Health Survey of Chile (Ministerio de Salud de Chile, 2010a), decreased slightly from $44 \%$ to $41 \%$. However, we observed an increase in overweight due to BMI (51.85\% of the subjects) in the older age group. Regarding obesity measured using BMI, this research showing that the older age group had the highest prevalence (present study 37.03\%, 35.8\%) were similar to the National Health Survey of Chile (Ministerio de Salud de Chile, 
TABLE 2 | Comparison of the scores on the eight scales of the SF-36 QoL questionnaire in subjects with obesity, abdominal obesity, and hypertension stratified by age group.

\begin{tabular}{|c|c|c|c|c|c|c|c|c|c|}
\hline \multirow{3}{*}{ QoL } & \multicolumn{2}{|c|}{ Obesity } & \multirow{3}{*}{$P^{*}$} & \multicolumn{2}{|c|}{ Abdominal obesity } & \multirow{3}{*}{$P^{*}$} & \multicolumn{2}{|c|}{ Hypertension } & \multirow{3}{*}{$P^{*}$} \\
\hline & Absent & Current & & Absent & Current & & Absent & Current & \\
\hline & \multicolumn{2}{|c|}{ Mean \pm SD } & & \multicolumn{2}{|c|}{ Mean \pm SD } & & \multicolumn{2}{|c|}{ Mean \pm SD } & \\
\hline \multicolumn{10}{|l|}{$\leq 44^{\mathrm{a}}$} \\
\hline PF & $53.83 \pm 7.45$ & $51.40 \pm 8.93$ & 0.339 & $55.36 \pm 6.76$ & $50.50 \pm 8.61$ & 0.046 & $53.19 \pm 7.731$ & $51.66 \pm 9.61$ & 0.617 \\
\hline $\mathrm{RP}$ & $50.75 \pm 9.59$ & $48.85 \pm 12.07$ & 0.569 & $50.99 \pm 9.50$ & $49.06 \pm 11.59$ & 0.556 & $49.03 \pm 10.95$ & $53.67 \pm 8.33$ & 0.244 \\
\hline RE & $52.56 \pm 8.29$ & $45.73 \pm 11.14$ & 0.026 & $53.49 \pm 8.64$ & $46.40 \pm 10.12$ & 0.018 & $49.20 \pm 10.47$ & $52.33 \pm 7.89$ & 0.409 \\
\hline $\mathrm{BP}$ & $48.33 \pm 8.08$ & $48.70 \pm 10.08$ & 0.894 & $44.31 \pm 6.85$ & $52.45 \pm 8.76$ & 0.001 & $48.85 \pm 8.69$ & $47.07 \pm 9.67$ & 0.597 \\
\hline SF & $50.10 \pm 11.36$ & $45.89 \pm 9.76$ & 0.216 & $51.19 \pm 7.73$ & $45.81 \pm 12.78$ & 0.104 & $48.55 \pm 10.29$ & $47.99 \pm 13.41$ & 0.892 \\
\hline $\mathrm{MH}$ & $53.05 \pm 9.32$ & $48.21 \pm 10.31$ & 0.117 & $53.67 \pm 8.25$ & $48.72 \pm 10.89$ & 0.101 & $51.37 \pm 8.97$ & $50.25 \pm 13.45$ & 0.767 \\
\hline $\mathrm{VT}$ & $49.51 \pm 8.89$ & $45.63 \pm 10.71$ & 0.203 & $49.69 \pm 10.48$ & $46.34 \pm 8.85$ & 0.263 & $49.03 \pm 7.90$ & $44.00 \pm 14.67$ & 0.170 \\
\hline $\mathrm{GH}$ & $49.62 \pm 9.33$ & $50.50 \pm 10.50$ & 0.774 & $46.92 \pm 6.97$ & $52.87 \pm 11.13$ & 0.042 & $50.50 \pm 9.18$ & $47.95 \pm 11.86$ & 0.490 \\
\hline \multicolumn{10}{|l|}{$\geq 45^{\mathrm{a}}$} \\
\hline PF & $47.44 \pm 13.78$ & $44.96 \pm 10.83$ & 0.663 & $48.42 \pm 8.22$ & $44.15 \pm 12.18$ & 0.375 & $46.39 \pm 9.85$ & $44.52 \pm 12.58$ & 0.672 \\
\hline $\mathrm{RP}$ & $46.76 \pm 9.69$ & $50.71 \pm 9.22$ & 0.399 & $52.12 \pm 7.73$ & $49.08 \pm 9.88$ & 0.446 & $48.66 \pm 9.07$ & $51.20 \pm 9.59$ & 0.487 \\
\hline RE & $53.27 \pm 9.50$ & $49.52 \pm 10.44$ & 0.469 & $52.12 \pm 9.99$ & $49.41 \pm 10.45$ & 0.539 & $48.45 \pm 9.80$ & $51.85 \pm 10.65$ & 0.398 \\
\hline $\mathrm{BP}$ & $51.27 \pm 10.90$ & $52.68 \pm 11.73$ & 0.809 & $46.80 \pm 5.94$ & $54.78 \pm 12.40$ & 0.096 & $51.96 \pm 10.28$ & $52.84 \pm 12.71$ & 0.846 \\
\hline SF & $51.57 \pm 8.42$ & $52.67 \pm 8.16$ & 0.789 & $49.81 \pm 9.22$ & $53.59 \pm 7.50$ & 0.274 & $53.59 \pm 5.81$ & $51.43 \pm 9.81$ & 0.497 \\
\hline $\mathrm{MH}$ & $51.40 \pm 7.68$ & $47.44 \pm 10.55$ & 0.439 & $51.16 \pm 8.56$ & $46.92 \pm 10.60$ & 0.326 & $44.42 \pm 8.62$ & $51.67 \pm 10.35$ & 0.060 \\
\hline $\mathrm{VT}$ & $49.91 \pm 11.12$ & $53.96 \pm 9.56$ & 0.413 & $53.24 \pm 11.53$ & $53.20 \pm 9.28$ & 0.992 & $56.41 \pm 11.18$ & $50.24 \pm 7.47$ & 0.102 \\
\hline $\mathrm{GH}$ & $52.28 \pm 15.00$ & $49.53 \pm 9.78$ & 0.610 & $49.57 \pm 14.45$ & $50.23 \pm 9.06$ & 0.887 & $51.28 \pm 10.33$ & $48.88 \pm 11.16$ & 0.567 \\
\hline \multicolumn{10}{|c|}{ Total sample } \\
\hline PF & $52.80 \pm 8.79$ & $47.77 \pm 10.43$ & 0.035 & $53.44 \pm 7.71$ & $47.56 \pm 10.77$ & 0.014 & $51.31 \pm 8.81$ & $47.31 \pm 11.82$ & 0.116 \\
\hline $\mathrm{RP}$ & $50.11 \pm 9.56$ & $49.90 \pm 10.45$ & 0.932 & $51.30 \pm 8.93$ & $49.07 \pm 10.70$ & 0.362 & $48.93 \pm 10.37$ & $52.17 \pm 9.00$ & 0.205 \\
\hline RE & $52.68 \pm 8.33$ & $47.87 \pm 10.77$ & 0.044 & $53.11 \pm 8.86$ & $47.80 \pm 10.26$ & 0.027 & $49.00 \pm 10.19$ & $52.04 \pm 9.47$ & 0.234 \\
\hline $\mathrm{BP}$ & $48.80 \pm 8.45$ & $50.94 \pm 11.08$ & 0.377 & $44.99 \pm 6.61$ & $53.53 \pm 10.52$ & $<0.001$ & $49.71 \pm 9.15$ & $50.58 \pm 11.73$ & 0.733 \\
\hline SF & $50.34 \pm 10.83$ & $49.72 \pm 9.41$ & 0.797 & $50.81 \pm 8.02$ & $49.41 \pm 11.24$ & 0.568 & $49.95 \pm 9.48$ & $50.09 \pm 11.19$ & 0.956 \\
\hline $\mathrm{MH}$ & $52.79 \pm 8.98$ & $47.78 \pm 10.31$ & 0.036 & $52.98 \pm 8.26$ & $47.88 \pm 10.66$ & 0.034 & $49.45 \pm 9.33$ & $51.11 \pm 11.38$ & 0.516 \\
\hline $\mathrm{VT}$ & $49.58 \pm 9.07$ & $50.33 \pm 10.79$ & 0.757 & $50.67 \pm 10.69$ & $49.52 \pm 9.58$ & 0.638 & $51.07 \pm 9.41$ & $47.80 \pm 11.00$ & 0.201 \\
\hline $\mathrm{GH}$ & $50.05 \pm 10.18$ & $49.95 \pm 9.98$ & 0.968 & $47.65 \pm 9.40$ & $51.65 \pm 10.18$ & 0.099 & $50.72 \pm 9.40$ & $48.52 \pm 11.18$ & 0.391 \\
\hline
\end{tabular}

QoL, quality of life; PF, physical function; RP, role limitations due to physical problems; RE, role limitations due to emotional problems; BP, bodily pain; SF, social functioning; $\mathrm{MH}$, mental health; VT, vitality; GH, general health perception; $P<0.05$ * $^{*}$ - test. ${ }^{a} \leq 44-\geq 45$, age categories (years).

2010a). A high prevalence of overweight and obesity evaluated by BMI in teachers was previously been reported for Chilean urban teachers (Cabrera et al., 2003; Kain et al., 2010), but the results were not stratified by age category. The usefulness of obesity evaluated by BMI is limited because it does not consider differences in corporal components (Prado et al., 2015). For this reason, in the present study, it was decided to define obesity according to \% FM. When obesity was measured by $\%$ FM, the obesity prevalence in rural teachers in the older age group $81.48 \%$, whereas when obesity was evaluated by BMI, the prevalence in the older age group was $37.03 \%$; therefore, there could be an underestimation of obesity in working-age population studies that use BMI.

Teachers belonging to the second age group ( $\geq 45$ years old) showed a higher prevalence $(51.85 \%)$ of high blood pressure than teachers in the same age group at the country level $(43.8 \%)$ in the National Health Survey of Chile (Ministerio de Salud de Chile, 2010a). This coincides with Cabrera et al. (2003), who also reported a higher prevalence of hypertension in teachers than that in the reference group. Regarding abdominal obesity and its categories stratified by age group in the National Health Survey of Chile (Ministerio de Salud de Chile, 2010a), a prevalence of $62.4 \%$ was observed for the group aged 25-44 years and $80.6 \%$ for the group aged 45-64 years. These values were far less than the values reported in the present study, with a prevalence of $79.6 \%$ in the younger group and $96.29 \%$ in the older group. These results indicate that cardiometabolic risk and metabolic syndrome are important factors (Despres et al., 2008).

Chronic conditions in rural teachers were mainly associated with the older age group, but the QoL MCS was affected by age. In Chile, teachers have a high workload that includes lessons and administration, as well as a series of working hours outside the classroom, which may include test review, planning, and educational material preparation. Additionally, tasks such as interacting with parents, solving school problems (inside and outside the classroom), and building relationships with peers, among others, may require an important social or emotional component (Cuenca et al., 2005). Therefore, this work overload may affect QoL, especially the MCS, of teachers, as observed in this study. Bauer et al. (2007) applied a general health 
TABLE 3 | Comparison of physical component and mental component summary measures for subjects with three chronic health conditions stratified according to age group.

\begin{tabular}{|c|c|c|c|c|c|c|}
\hline & \multicolumn{2}{|c|}{$\leq 44^{\mathrm{a}}$} & \multicolumn{2}{|c|}{$\geq 45^{a}$} & \multicolumn{2}{|c|}{ Total sample } \\
\hline & PCS & MCS & PCS & MCS & PCS & MCS \\
\hline & Mean \pm SD & Mean \pm SD & Mean \pm SD & Mean \pm SD & Mean \pm SD & Mean \pm SD \\
\hline \multicolumn{7}{|l|}{ Fat mass (\%) } \\
\hline Non-obese & $47.62 \pm 5.75$ & $49.59 \pm 8.05$ & $45.34 \pm 7.87$ & $51.21 \pm 7.78$ & $47.25 \pm 6.04$ & $49.85 \pm 7.90$ \\
\hline Obese & $48.56 \pm 6.33$ & $42.96 \pm 5.23$ & $47.13 \pm 5.32$ & $48.90 \pm 8.02$ & $47.76 \pm 5.75$ & $46.31 \pm 7.48$ \\
\hline$P^{*}$ & 0.616 & 0.004 & 0.538 & 0.564 & 0.723 & 0.059 \\
\hline \multicolumn{7}{|l|}{ Blood pressure } \\
\hline Non-hypertensive & $48.14 \pm 4.99$ & $47.08 \pm 6.66$ & $48.17 \pm 4.99$ & $47.76 \pm 7.74$ & $48.15 \pm 4.93$ & $47.26 \pm 6.98$ \\
\hline Hypertensive & $47.33 \pm 9.02$ & $46.55 \pm 11.43$ & $45.53 \pm 6.26$ & $50.79 \pm 8.01$ & $46.27 \pm 7.32$ & $49.13 \pm 9.48$ \\
\hline$P^{*}$ & 0.752 & 0.859 & 0.240 & 0.327 & 0.209 & 0.351 \\
\hline \multicolumn{7}{|l|}{ Abdominal obesity } \\
\hline Normal & $46.08 \pm 5.72$ & $50.68 \pm 7.51$ & $45.92 \pm 6.13$ & $50.50 \pm 7.23$ & $46.04 \pm 5.72$ & $50.63 \pm 7.30$ \\
\hline Obese & $49.82 \pm 5.66$ & $43.43 \pm 6.24$ & $47.17 \pm 5.69$ & $48.84 \pm 8.28$ & $48.59 \pm 5.76$ & $45.93 \pm 7.66$ \\
\hline$P^{*}$ & 0.037 & 0.001 & 0.615 & 0.626 & 0.071 & 0.012 \\
\hline
\end{tabular}

PCS, physical component summary; MCS, mental component summary; SD, standard deviation. ${ }^{a} \leq 44-\geq 45$, age categories (years). ${ }^{*}$ Mann-Whitney-Test. $P<0.05$.

TABLE 4 | Logistic regressions for the association of 25th percentiles of MCS and PCS with chronic health conditions adjusted by age and gender.

\begin{tabular}{|c|c|c|c|c|}
\hline & \multicolumn{2}{|c|}{ MCS } & \multicolumn{2}{|c|}{ PCS } \\
\hline & OR $[95 \% \mathrm{Cl}]^{\mathrm{a}}$ & $P$ & OR $[95 \% \mathrm{Cl}]^{\mathrm{a}}$ & $P$ \\
\hline One condition & 1.133 [0.063-20.202] & 0.932 & 3.219 [0.508-20.390] & 0.215 \\
\hline Two conditions & 16.995 [1.741-165.900] & 0.015 & 2.402 [0.383-15.070] & 0.940 \\
\hline Three conditions & 82.616 [4.579-1490.49] & 0.003 & $1.283[0.114-4.331]$ & 0.840 \\
\hline Age ( $\leq 44$ years old $)$ & 8.820 [1.565-49.698] & 0.014 & 0.577 [0.165-2.015] & 0.389 \\
\hline Gender (female) & $0.842[0.188-3.772]$ & 0.823 & 0.477 [0.145-1.565] & 0.223 \\
\hline Hosmer-Lemeshow & 0.606 & & 0.427 & \\
\hline
\end{tabular}

PCS, physical component summary; MCS, mental component summary. ${ }^{a}$ Odds Ratios [Confidence interval]. $P<0.05$.

questionnaire and found that the MCS was affected in 30\% of German urban school teachers. Therefore, it is important to generate mitigation strategies, such as social networks inside and outside the classroom, to promote $\mathrm{MH}$ in teachers.

In addition, in this study, a low score in the MCS of the QoL survey was associated with the simultaneous presence of two and three chronic health conditions in rural teachers, even after adjustment for gender. We adjusted for gender because the teachers who participated in this study were mostly women (68.57\%), an aspect that coincides with previous studies in Chilean school teachers (Cabrera et al., 2003; Cuenca et al., 2005). The significant associations between the MCS and the chronic conditions indicate that teachers should have ways to prevent and identify $\mathrm{MH}$ issues and strategies to improve their health, thus improving their QoL. Interestingly, teachers perceive MCS deterioration but not PCS deterioration, which can be related to the varied high-stress tasks that the teaching profession entails in Chile. Accordingly, Chile has one of the highest medical leave rates in South America (Cuenca et al., 2005), and these medical leave rates are often associated with emotional fatigue, which corresponds to the results of our work, as lower MCS scores were associated with chronic conditions.
The present study has several limitations. The first is typical of cross-sectional research; one of the instruments used, the QoL survey, was based on self-reports, so no causality can be derived from the reported associations. Nevertheless, we obtained a high response rate from teachers. Additionally, although we investigated a representative sample of rural teachers, we worked in only two rural areas in a region of Chile, which may limit the generalization of the study results to other regions. Further studies should include teachers in urban areas who may have other conditions that affect their QoL. Although there are important studies on the QoL of urban teachers (Fernandes and Rocha, 2009; Yang et al., 2009; Pizolato et al., 2013; Nusseck et al., 2018), there are few studies focusing on the health of rural teachers; therefore, the present study has the strength of being a pioneer study involving rural teachers, health and QoL.

Currently, occupational health in Chile confers safety and prevention to workers in general but not specifically to school teachers. Therefore, this research has an important implication in enhance the background on health in rural school teachers, providing a clear picture to establish possible improvements and implementation of public policies in the prevention of mental and physical health of school teachers. In this sense, 
Arvidsson et al. (2016) suggests a series of measures for teachers at the social, organizational and individual levels. At the organizational and individual level that improve leadership and strengthen school teacher self-efficacy. They also suggest improving coordination between the various stakeholders, the rationalization of administrative tasks and better ergonomic conditions during work, aspects that point to the mental and physical health components. In addition, and given the lack of time that has been reported in Chilean school teachers (Cuenca et al., 2005) should include policies for balancing work life and leisure time, in order to generate healthy living spaces and reduce the prevalence of CNCDs in school teachers.

\section{CONCLUSION}

In conclusion, chronic health conditions mainly affect the QoL MCS rather than the PCS in rural teachers. This suggests that sufficient resources must be available to detect and manage early chronic conditions in teachers in rural areas since chronic conditions are associated with the MCS. Teaching is an occupation that requires significant mental work, and chronic conditions affecting the MCS could affect work performance and thus affect the students.

\section{DATA AVAILABILITY STATEMENT}

The datasets generated for this study are available on request to the corresponding author.

\section{REFERENCES}

Arvidsson, I., Håkansson, C., Karlson, B., Björk, J., and Roger Persson, R. (2016). Burnout among Swedish school teachers - a cross-sectional analysis. BMC Public Health 16:823. doi: 10.1186/s12889-016-3498-7

Bagtasos, M. R. (2011). Quality of work life: a review of literature. DLSU Bus. Econ. Rev. 20, 1-8.

Bauer, J., Unterbrink, T., Hack, A., Pfeifer, R., Buhl-Griesshaber, V., Muller, U., et al. (2007). Working conditions, adverse events and mental health problems in a sample of 949 German teachers. Int. Arch. Occup. Environ. Health 80, 442-449. doi: 10.1007/s00420-007-0170-7

Bogaert, I., De Martelaer, K., Deforche, B., Clarys, P., and Zinzen, E. (2014). Associations between different types of physical activity and teachers' perceived mental, physical, and work-related health. BMC Public Health 14:534. doi: 10.1186/1471-2458-14-534

Bringi, S. C., and Ranbhare, K. N. (2015). Stress among the teachers working women with special reference to secondary school in Belagavi, Karnataka state: a study. Int. J. Soc. Sci. Humanit. Res. 3, 221-225.

Bravo, M. B. (2005). Validación del Maslach Burnout Inventory (MBI), en Dirigentes del Colegio de Profesores A.G. de Chile. Chile: Universidad de Chile.

Cabrera, G. V., Bravo, C. A., Silva, G. B., Muller, N. M., Freire, A. M., and Goldenberg, J. S. (2003). Estudio de la Salud Laboral de los Profesores en Chile: Informe Final de Proyecto. Chile: Pontificia Universidad Católica de Chile.

Chávez, R. C. (2009). Condiciones de trabajo y bienestar/malestar docente en profesores de enseñanza media de Santiago de Chile. Educ. Soc. 30, 409-426. doi: 10.1590/s0101-73302009000200006

Cuenca, R., Garzón, E. F., Kohen, J., Garrido, M. P., Guzmán, L. R., Tomasina, F., et al. (2005). Condiciones de Trabajo y Salud Docente: Estudios de Casos

\section{ETHICS STATEMENT}

The studies involving human participants were reviewed and approved by the Pontificia Universidad Católica de Valparaíso. The patients/participants provided their written informed consent to participate in this study.

\section{AUTHOR CONTRIBUTIONS}

PL designed the study. PL and GV-F performed the measurements, processed the data, drafted the manuscript, and designed the tables. PL and LL performed the statistical analysis. All authors discussed the results and commented on the manuscript.

\section{FUNDING}

This research was supported by the FONDECYT Grant No. 11170716 (FONDECYT-CONICYT, Chile) and the Vicerrectoría de Investigación y Estudios Avanzados of the Pontificia Universidad Católica de Valparaíso through project 039.346/2016.

\section{ACKNOWLEDGMENTS}

The authors thank the directors and teachers of all the rural schools in La Calera and Hijuelas for their willingness to participate in this study.

en Argentina, Chile, Ecuador, México, Perú y Uruguay. Santiago de Chile: UNESCO.

Despres, J.-P., Lemieux, I., Bergeron, J., Pibarot, P., Mathieu, P., Larose, E., et al. (2008). Abdominal obesity and the metabolic syndrome: contribution to global cardiometabolic risk. Arterioscler. Thromb. Vasc. Biol. 28, 1039-1049. doi: 10. 1161/ATVBAHA.107.159228

Fernandes, M. H., and Rocha, V. M. (2009). Impact of the psychosocial aspects of work on the quality of life of teachers. Braz. J. Psychiatry 31, 15-20. doi: 10.1590/s1516-44462009000100005

Flegal, K. M., Carroll, M. D., Kit, B. K., and Ogden, C. L. (2012). Prevalence of obesity and trends in the distribution of body mass index among US adults, 1999-2010. JAMA 307, 491-497. doi: 10.1001/jama.2012.39

Freude, G., Seibt, R., Pech, E., and Ullsperger, P. (2005). Assessment of work ability and vitality - a study of teachers of different age groups. Int. Congr. Ser. 1280, 270-274. doi: 10.1016/j.ics.2005.02.099

Innstrand, S. T., Langballe, E. M., Falkum, E., and Aasland, O. G. (2011). Exploring within- and between-gender differences in burnout: 8 different occupational groups. Int. Arch. Occup. Environ. Health 84, 813-824. doi: 10.1007/s00420011-0667-y

Johnson, S., Cooper, C., Cartwright, S., Donald, I., Taylor, P., and Millet, C. (2005). The experience of work-related stress across occupations. J. Manag. Psychol. 20, 178-187. doi: 10.1108/02683940510579803

Jurado, M. D. M. M., Perez-Fuentes, M. D. C., Atria, L., Ruiz, N. F. O., and Linares, J. J. G. (2019). Burnout, perceived efficacy, and job satisfaction: perception of the educational context in high school teachers. Biomed. Res. Int. 2019:1021408. doi: 10.1155/2019/1021408

Kain, J., Leyton, B., Concha, F., Salazar, G., Lobos, L., and Vio, F. (2010). Estrategia de prevención de obesidad en escolares: efecto de un programa aplicado a sus profesores (2007-2008). Rev. Méd. Chile 138, 181-187. 
McDowell, I., and McDowell, I. (2006). "General health status and quality of life," in Measuring Health: a Guide to Rating Scales and Questionnaires (New York, NY: Oxford University Press), 520-702.

MINEDUC (2016). Centro de Estudios. Centro de Estudios MINEDUC. Available at: http://centroestudios.mineduc.cl/tp_modulos/tpm_seccion/contVentana. php?cc=2179 (accessed January 29, 2016).

Ministerio de Salud de Chile, (2010a). Encuesta Nacional de Salud (ENS) Chile 2009-2010. Santiago de Chile: Gobierno de Chile.

Ministerio de Salud de Chile, (2010b). Guia Clínica Hipertension Arterial Primaria o Escencial en Personas de 15 Años y Mas. Santiago de Chile: Gobierno de Chile.

Nusseck, M., Spahn, C., Echternach, M., Immerz, A., and Richter, B. (2018). Vocal health, voice self-concept and quality of life in german school teachers. J. Voice S0892-1997, 30311-30314. doi: 10.1016/j.jvoice.2018.11.008

OIT, (2003). Actividades Normativas de la OIT en el Ambito de la Seguridad y la Salud en el Trabajo: Estudio Detallado Para la Discusión con Miras a la Elaboración de un Plan de Acción Sobre Dichas Actividades. Ginebra: Organización Internacional del Trabajo.

Olivares, P. (2006). Estado de Salud de Beneficiarios del Sistema de Salud de Chile 2004 2005. Estudio de validación Cuestionario SF 36. Chile: Superintendence of Isapres.

Pimenta, F. B., Bertrand, E., Mograbi, D. C., Shinohara, H., and LandeiraFernandez, J. (2015). The relationship between obesity and quality of life in Brazilian adults. Front. Psychol. 6:966. doi: 10.3389/fpsyg.2015.00966

Pizolato, R., Rehder, M., Meneghim, M., Ambrosano, G., Mialhe, F., and Pereira, A. C. (2013). Impact on quality of life in teachers after educational actions for prevention of voice disorders: a longitudinal study. Health Qual. Life Outcomes 11:28. doi: 10.1186/1477-7525-11-28

Porto, L. A., Carvalho, F. M., Oliveira, N. F. D., Neto, A. M. S., Araújo, T. M. D., Reis, E. J. F. B. D., et al. (2006). Associação entre distúrbios psíquicos e aspectos psicossociais do trabalho de professores. Rev. Saúde Públ. 40, 818-826. doi: 10.1590/s0034-89102006005000001

Prado, C. M., Gonzalez, M. C., and Heymsfield, S. B. (2015). Body composition phenotypes and obesity paradox. Curr. Opin. Clin. Nutr. Metab. Care 18, 535-551. doi: 10.1097/MCO.0000000000000216
The World Medical Association, (2009). Declaration of Helsinki. Ethical Principles for Medical Research Involving Human Subjects (Declaration of Helsinki). 59th WMA General Assembly. Seoul: World Medical Association.

Travers, C. J., and Cooper, C. L. (1993). Mental health, job satisfaction and occupational stress among UK teachers. Work Stress 7, 203-219. doi: 10.1080/ 02678379308257062

Trevisol, D. J., Moreira, L. B., Kerkhoff, A., Fuchs, S. C., and Fuchs, F. D. (2011). Health-related quality of life and hypertension: a systematic review and metaanalysis of observational studies. J. Hypertens. 29, 179-188. doi: 10.1097/HJH. 0b013e328340d76f

Unterbrink, T., Zimmermann, L., Pfeifer, R., Wirsching, M., Brahler, E., and Bauer, J. (2008). Parameters influencing health variables in a sample of 949 German teachers. Int. Arch. Occup. Environ. Health 82, 117-123. doi: 10.1007/s00420008-0336-y

Vinaccia, S., and Orozco, L. M. (2005). Aspectos psicosociales asociados con la calidad de vida de personas con enfermedades crónicas. Diversitas 1, $125-137$.

Ware, J. E. Jr., and Sherbourne, C. D. (1992). The MOS 36-item short-form health survey (SF-36). I. Conceptual framework and item selection. Med. Care 30, 473-483. doi: 10.1097/00005650-199206000-00002

Yang, X., Ge, C., Hu, B., Chi, T., and Wang, L. (2009). Relationship between quality of life and occupational stress among teachers. Public Health 123, 750-755. doi: 10.1016/j.puhe.2009.09.018

Conflict of Interest: The authors declare that the research was conducted in the absence of any commercial or financial relationships that could be construed as a potential conflict of interest.

Copyright (c) 2020 Lizana, Vega-Fernandez and Lera. This is an open-access article distributed under the terms of the Creative Commons Attribution License (CC BY). The use, distribution or reproduction in other forums is permitted, provided the original author(s) and the copyright owner(s) are credited and that the original publication in this journal is cited, in accordance with accepted academic practice. No use, distribution or reproduction is permitted which does not comply with these terms. 